\title{
Neuroimaging Insight into the Link between Depression and Insomnia: A Systematic Review
}

Shadi Bagherzadeh-Azbari ${ }^{1,2^{\star}}$ M.Sc., Habibolah Khazaie ${ }^{3^{*}}$ M.D., Mojtaba Zarei ${ }^{1}$ M.D. Ph.D., Kai

Spiegelhalder ${ }^{4}$ Ph.D., Martin Walter ${ }^{5,6}$ M.D. PhD, Jeanne Leerssen ${ }^{7}$ M.Sc., Eus J. Van

Someren $^{7,8}$ Ph.D., Amir A. Sepehry ${ }^{9}$ M.Sc., Ph.D. Masoud Tahmasian ${ }^{1 ¥}$ M.D. Ph.D.

* S.B and H.K. contributed equally to this work.

1 Institute of Medical Sciences and Technology, Shahid Beheshti University, Tehran, Iran.

2 Department of Psychology, Humboldt University of Berlin, Berlin, Germany.

3 Sleep Disorders Research Center, Kermanshah University of Medical Sciences, Kermanshah, Iran.

4 Department of Psychiatry and Psychotherapy, Medical Centre - University of Freiburg, Faculty of Medicine, University of Freiburg, Germany.

5 Department of Psychiatry, University of Tübingen, Tübingen, Germany.

6 Clinical Affective Neuroimaging Laboratory, Leibniz Institute for Neurobiology, Otto-von-Guericke University, Magdeburg, Germany

7 Department of Sleep and Cognition, Netherlands Institute for Neuroscience, an institute of the Royal Netherlands Academy of Arts and Sciences, 1105 BA, Amsterdam, Netherlands.

8 Departments of Psychiatry and Integrative Neurophysiology, Center for Neurogenomics and Cognitive Research (CNCR), Amsterdam Neuroscience, Vrije Universtiteit Amsterdam, Amsterdam UMC, De Boelelaan 1085, 1081 HV Amsterdam, The Netherlands.

9 Adler University, Vancouver, BC, Canada.

¥ Corresponding Author: Dr. Masoud Tahmasian, Institute of Medical Sciences and Technology, Shahid Beheshti University, Velenjak, PO. 1983969411, Tehran, Iran. E-mail address: m_tahmasian@sbu.ac.ir

Running title: Insomnia in Major Depressive Disorders

Count: Title (12), Abstract (230), Text (5751), References (125), Figure (2), Table (1). 


\section{Abstract}

Background: Insomnia is a symptom of Major Depressive Disorder (MDD) and genome wide association studies pointed to their strong genetic association. Although the prevalence of insomnia symptoms in MDD is noticeable and evidence supports their strong bidirectional association, the number of available neuroimaging findings on patients with MDD with insomnia symptoms is limited. However, such neuroimaging studies could verily improve our understanding of their shared pathophysiology and advance corresponding theories.

Methods: Based on the preferred reporting items for systematic reviews and meta-analysis guideline, we have conducted a literature search using PubMed, EMBASE, and Scopus databases and systematically explored 640 studies using various neuroimaging modalities in MDD patients with different degrees of insomnia symptoms.

Results: Despite inconsistencies, current findings from eight studies suggested structural and functional disturbances in several brain regions including the amygdala, prefrontal cortex and anterior cingulate cortex and insula. The aberrant functional connectivity within and between the main hubs of the salience and default mode networks could potentially yield new insights into the link between MDD and insomnia, which needs further assessment.

Limitations: The number of studies reviewed herein is limited. The applied methods for assessing structural and functional neural mechanisms of insomnia and depression were variable.

Conclusion: Neuroimaging methods demonstrated the overlapping underlying neural mechanisms between MDD and insomnia. Future studies may facilitate better understanding of the uniqueness of each condition to allow development of specific treatment.

Key words: Major depressive disorder; Insomnia; fMRI; PET; SPECT; Spectroscopy. 


\section{Introduction}

Major Depressive Disorder (MDD) is an important cause of disability in the human population (American Psychiatric Association, 2013), also considered as one of the most common severe psychiatric disorders (Kessler et al., 2007; Waraich et al., 2004). According to the World Health Organization (WHO), $25 \%$ of the general population present symptoms consistent with a depressive episode at some time in their lives (Lepine and Briley, 2011). Based on Diagnostic and Statistical Manual of Mental Disorders-fifth edition (DSM-5), MDD is characterized by depressed mood, decreased or loss of pleasure, reduced or increased craving for food, loss of energy, psychomotor agitation or retardation, and changes in sleep profile (American Psychiatric Association, 2013). Several studies indicated that sleep problems are present in patients with MDD (Khazaie et al., 2013; Park et al., 2013; Soehner et al., 2014; Tsuno et al., 2005). Interestingly, $40 \%$ of MDD patients report insomnia symptoms before appearance of a depressive episode, and $22 \%$ report to have simultaneous occurrence of depressive symptoms with insomnia (Ohayon and Roth, 2003).

Insomnia is defined by complaints of initiating or maintaining sleep, which is associated with subjective distress and functional impairment during daytime (Morin et al., 2015). Importantly, insomnia is not only a frequent symptom of various psychiatric disorders (Emamian et al., 2019; Hung et al., 2018; Khazaie et al., 2013; Morin et al., 2015; Okun, 2016; Tahmasian et al., 2017), but also an important risk factor for the development of depression (Baglioni et al., 2011; Emamian et al., 2019). Individuals suffering from insomnia compared to individuals without insomnia are nearly twice as likely to develop depression in the future (Baglioni et al., 2011; Franzen and Buysse, 2008; Perlis et al., 2006). Indeed, different symptoms of insomnia such as daytime fatigue, sleep maintenance problems and light sleep and also early morning awakenings are typical sleep disturbances in MDD (Franzen and Buysse, 2008). Although to date, a causal relationship between insomnia and depression has not been confirmed, insomnia 
has been underscored as a significant contributor of disability due to MDD (Baglioni et al., 2011; Thase, 2006). It has also been suggested that abnormal emotional reactivity modulates the relationship between insomnia and depression (Baglioni et al., 2010).

There is also a strong genetic correlation between insomnia and depressive symptoms (Franzen and Buysse, 2008). Recent Genome wide association studies observed a strong link between insomnia and major depression (Hammerschlag et al., 2017; Jansen et al., 2018; Lane et al., 2018; Stein et al., 2018). Also, the GWAS studies in insomnia suggested possible involvement of a few cortical and subcortical areas including the caudate nucleus and Brodmann areas 9 and 24, striatum, claustrum, and hypothalamus, where gene expression profiles show above-chance resemblance to the genetic risk profile of insomnia disorder (Jansen et al., 2018). Additionally, volume of hippocampus and MDD share similar genetic variants (Wigmore et al., 2017). Structural and functional changes in hippocampus and amygdala have been demonstrated in both insomnia and MDD (Baglioni et al., 2014; Joo et al., 2014; Riemann et al., 2007; Tahmasian et al., 2013). However, two separate neuroimaging meta-analyses on MDD and also insomnia disorder suggested inconsistency of structural atrophy and functional impairments across previous studies (Muller et al., 2017; Tahmasian et al., 2018).

Recently, neuroimaging technology has opened a unique opportunity to evaluate different functional, molecular and neurochemical processes in the brain and to study their interaction in vivo, particularly in depression and insomnia, which had a great impact on understanding their pathophysiology (Desseilles et al., 2008; Desseilles et al., 2011; Kambeitz et al., 2017; Khazaie et al., 2017; Muller et al., 2017; Spiegelhalder et al., 2015). However, few neuroimaging studies have directly investigated the link between MDD and insomnia. The present review provides an overview of existing studies pertaining to the neuroimaging link between insomnia and depression. Through the lenses of various neuroimaging techniques, we 
particularly provide a general view to extend our understanding of the neurocognitive association between depression and insomnia with a synthesis of the blueprint findings of their shared pathophysiology. Thus, we have divided relevant studies by using specific neuroimaging tools, including single-photon emission computed tomography (SPECT), positron emission tomography (PET), structural magnetic resonance imaging (sMRI), functional MRI (fMRI), magnetic resonance spectroscopy (MRS), and near-infrared spectroscopy (NIRS). For each section, we first provide a brief introduction of the special neuroimaging modality used in each study, and subsequently discuss the contribution of previous observations in the context of a shared network model, which could explain the mechanism underlying the link between MDD and insomnia. These studies included seven cross-sectional and one longitudinal study.

\section{Search Strategy}

Our search strategy was based on the preferred reporting items for systematic reviews and meta-analyses statement "PRISMA" (Moher et al., 2009). The search was conducted using PubMed, EMBASE and Scopus in June 2018, and reference tracking of identified papers and reviews. The keywords were insomnia AND (depress* OR "major depressive disorder" OR MDD) AND (fMRI OR "functional MRI" OR "functional magnetic resonance imaging" OR "positron emission tomography" OR PET OR "single-photon emission computed tomography" OR SPECT OR VBM OR "voxel-based morphometry" OR spectroscopy "Near-infrared spectroscopy" OR NIRS OR "diffusion tensor imaging" OR DTI)". We retrieved 640 studies and included studies that investigated insomnia symptoms in patients with MDD using structural or functional neuroimaging techniques. The exclusion criteria were non-English literature, reviews, meta-analyses, editorial letters, case reports, patients without diagnosis of MDD coexisting with insomnia symptoms, and other unrelated topics. The final dataset included eight studies that applied different neuroimaging modalities including SMRI (one), fMRI (three), PET (one), SPECT 
(one), NIRS (one), and MRS (one) (Table 1, Figure 1). The review was pre-registered on PROSPERO (CRD42018108340).

\section{MRI studies}

MRI is a non-invasive imaging method with high spatial resolution without using ionizing radiation (Hirsch, 2015). The brain's tissues can be visualized based on high-quality threedimensional MRI images (Bunge and Kahn, 2009). In particular, SMRI is well suited technique to visualize and analyze the anatomical properties and abnormalities in the brain (Hirsch, 2015). Voxel-based morphometry is a measurement based on T1-weighted MRI images, which has been broadly used to quantify volume of cortical and subcortical brain areas. Studies that applied VBM found volume reduction in the amygdala, hippocampus, anterior cingulate cortex $(A C C)$, and prefrontal cortex (PFC) in MDD, in general, but did not separate people with and without insomnia among them (Bora et al., 2012; Tahmasian et al., 2013; Vassilopoulou et al., 2013). The mentioned regions are involved in emotional processing and their dysfunctions are associated with important features of MDD pathophysiology (Ritchey et al., 2011). For instance, one group investigated the volume of several brain regions in 23 patients with melancholic MDD, 17 patients with psychotic MDD, and 18 normal controls (Vassilopoulou et al., 2013). This study found larger amygdala volumes and smaller left anterior subgenual ACC volumes in both depressed groups compared to healthy individuals. Moreover, regardless of the depression subtypes, the amygdala volume was significantly larger in MDD patients with insomnia compared to MDD patients without insomnia (Vassilopoulou et al., 2013). Of note, the amygdala is a well-known area for playing an important role not only in emotional processing but - at least in rodents - in controlling rapid-eye-movement (REM) sleep (Xi et al., 2012). This engagement could be described by the patterns of glutamatergic projections from the central nucleus of the 
amygdala to the nucleus pontis oralis, which is a critical brainstem location responsible for the generation and maintenance of sleep (Fung et al., 2011).

Functional MRI (fMRI) is another widely used tool to identify brain activity based on blood oxygenation level dependence (BOLD) signal alterations, which are related to particular cognitive tasks or intrinsic brain organization in the resting-state condition (Bunge and Kahn, 2009; Liu et al., 2015). Few fMRI studies used task paradigms or the resting-state condition offering great potential to investigate the neurobiology of MDD and insomnia separately. For review see (Kaiser et al., 2015; Khazaie et al., 2017; Muller et al., 2016). Reward-related dysfunction has been suggested as an important factor in the development of depressive symptoms. Findings suggest that altered neural responses to reward cues might be involved in the risk that insomnia symptoms during early adolescence convey to depressive symptoms in later adolescence (Casement et al., 2016). Poor sleep quality and sleep deprivation are associated with altered reactivity to affective stimuli and reduced activity mainly in the right parietal cortex (Javaheipour et al., 2019). One study examined BOLD activity in four brain regions (striatum, medial PFC (mPFC), orbitofrontal cortex (OFC) and amygdala) during an anticipation of reward task in 123 adolescent girls with different levels of difficulty falling and staying asleep, and non-restorative sleep (Casement et al., 2016). These symptoms define, or are common, in insomnia, and are associated with depressive symptoms (Edinger et al., 2004). The study revealed that the onset of non-restorative sleep during early adolescent predicts altered dorsal mPFC reward-related BOLD responses in late adolescence. In brief, insomnia symptoms predict later alterations in reward processing in adolescents (Casement et al., 2016).

Another study using fMRI technique looked into the group differences between MDD patients with high insomnia, MDD patients with low insomnia and healthy controls (Liu et al., 2018). The study used fMRI to compare the differences in the amplitude of low-frequency 
fluctuations (ALFF) during resting state condition in brain regions such as right inferior frontal gyrus/anterior insula (IFG/AI), bilateral dorsolateral prefrontal cortex (dIPFC), right middle temporal gyrus and left calcarine between the three groups. Regions of interest analyses found significant differences in ALFF between the three groups of participants in these brain regions. Furthermore, this study found that increased ALFF in the right IFG/AI seems to indicate an anomaly specific to insomnia in MDD, whereas increases in the bilateral dIPFC indicate an anomaly specific to MDD in general. Even when controlling for depression and anxiety - which was assessed using Hamilton Anxiety Rating Scale - increased ALFF in the right IFG/AI correlated with severity of insomnia symptoms. Therefore, a main conclusion drawn from this study is that, regardless of anxiety and depression symptoms, increased ALFF in IFG/AI during resting state may be connected to hyperarousal in MDD patients with insomnia symptoms (Liu et al., 2018).

At the molecular level, clock genes play a critical role in producing circadian rhythms in all physiological, behavioral and cognitive processes (Lowrey and Takahashi, 2000), including sleep and wakefulness (Saper et al., 2005). Their cyclic expression occurs not only in the suprachiasmatic nuclei, the biological clock of the brain, but also in several other brain structures, including the cingulate cortex (Abe et al., 2001). Preliminary findings underline a higher occurrence of insomnia among MDD patients that are homozygote for the $3111 / \mathrm{C}$ variant polymorphism in the flanking region of the CLOCK gene (Serretti et al., 2003). To assess the neural correlates and rhythm activities in the cingulate cortex using fMRI, one study collected data from 30 patients with major depressive episodes, who performed the Go/No-Go decision task of moral valence using positive and negative words. This study showed significant interaction between the moral valance of the stimuli and the genotype in both posterior and anterior cingulate cortex in patients. The eight carriers of the CLOCK $3111 \mathrm{C}$ allele among these 
patients had an increased lifetime and episodic concurrency of insomnia during the depressive episodes and moreover the worst MDD treatment responses. This study demonstrated that mood-disordered carriers of the $3111 \mathrm{C}$ variant had higher rate of insomnia across lifetime and also during the depressive episodes of patients (Benedetti et al., 2008).

In summary, these preliminary findings illustrated how sMRI and fMRI can be used to study the structural and functional alterations related to insomnia symptoms among patients with MDD. Of note, we identified one study using the sMRI method and three with the fMRI modality.

\section{PET and SPECT studies}

During the past decades, PET and SPECT provided clues to the etiology of neuropsychiatric disorders like MDD (Hamilton et al., 2012) and insomnia (Spiegelhalder et al., 2015). PET is a nuclear imaging technique, which relies on radiotracers to provide 3D images of tissue function (Rahmim and Zaidi, 2008), with few advantages compared to fMRI. PET is 1) immune to the loss of signal at air-tissue interfaces, 2) has scanning environment that is less acoustically disturbing than the MRI environment, and 3) can measure activity of various neurotransmitters, as well as neural glucose metabolism using 2-[ $\left.{ }^{18} \mathrm{~F}\right]$-fluoro-2-deoxy-d-glucose (FDG) (Catana et al., 2013). FDG-PET scan has become the most widely used radiopharmaceutical tracer in the clinical imaging of neuropsychiatric conditions (Hoh, 2007). SPECT is another nuclear imaging modality measuring the regional cerebral blood flow (rCBF) in the brain and producing 3D images using gamma rays (Sataloff et al., 1996). Taken together, PET and SPECT can serve to find clues on functional abnormalities in neuropsychiatric disorders (Rahmim and Zaidi, 2008).

The rostral and ventral regions of the ACC in human brain are involved in a wide array of affective and autonomic functions as well as motivational behaviors (Mayberg et al., 1997). MDD patients were found to have decreased activity (Manoliu et al., 2014) and volumetric 
alterations (Koolschijn et al., 2009) in the rostral and ventral ACC and in the dIPFC. The ACC is an important region in patients with insomnia disorder (Winkelman et al., 2013). Investigating the association between $\mathrm{rCBF}$ and specific symptom dimensions in MDD obtained with the Hamilton Depression Rating Scale (HDRS), a case-control study found a negative correlation between insomnia severity and $\mathrm{rCBF}$ in the subgenual and right rostral $\mathrm{ACC}$, claustrum, and insula (Perico et al., 2005). Briefly, the HDRS was administered following a structured clinical interview to record the intensity of initial, middle and late insomnia. This study confirmed earlier studies highlighting the role of ACC in the pathophysiology of both MDD and insomnia (Mayberg et al., 1999; Spiegelhalder et al., 2015). Interestingly, the ACC and claustrum were also identified among the few brain areas where gene expression profiles show above-chance resemblance to the genetic risk profile of insomnia disorder (Jansen et al., 2018).

Considering the monoamine transmission theory and the importance of neurotransmitter serotonin (5-HT) in MDD (Kaufman et al., 2016), it has been suggested that both reduced serotonin levels and sleep-wake cycle regulation could serve as an indicator for insomnia (Morin et al., 2015). The serotonin receptor subtype (5-HT1A) has been implicated in the effects of antidepressants. A case-control PET study on 17 drug-naive MDD patients found a higher probability of early insomnia symptoms in patients with a lower 5-HT1A receptor binding potential in the ventral part of ACC, dIPFC and angular gyrus (Hirvonen et al., 2008). It has been shown that insomnia in depression reflects a compensatory phenomenon to reverse deficient 5$\mathrm{HT}_{1} \mathrm{~A}$ function, as sleep deprivation increases 5-HT1A function (Adrien, 2002). The similar neurobiological mechanisms of sleep deprivation and serotonergic antidepressant medications suggest a common endogenous compensatory process (Adrien, 2002). 


\section{MRS studies}

In-vivo MRS is another non-invasive technique that is used to track metabolic activity in the brain. To date, MRS has played a significant role in diagnosing and monitoring patients with metabolic disorders (Ross and Bluml, 2001) by using hydrogen proton $(1 \mathrm{H})$ signals to measure biochemical changes in the brain (Jansen et al., 2006). Previous 1H-MRS studies in patients with MDD revealed a reduction in the inhibitory neurotransmitter $\gamma$-aminobutyric acid $(G A B A)$ in the PFC and ACC (Bhagwagar et al., 2008; Hasler et al., 2007; Price et al., 2009). Interestingly, GABA reduction has also been mentioned as a factor that could sustain insomnia symptoms (Winkelman et al., 2008). In order to investigate the role of the GABAergic system in insomnia, a cross-sectional study measured the GABA-creatine ratio (GABA/Cr) in the ACC, occipital cortex, and thalamus in 20 adults with insomnia symptoms and 20 healthy subjects (Plante et al., 2012). The results demonstrated significant lower GABA/Cr in the ACC and occipital cortex in insomnia patients compared to healthy subjects, that by tautology suggesting overlapping neurochemical alterations in MDD and insomnia (Plante et al., 2012). Future cross-sectional studies comparing these brain regions directly between patients with insomnia to those with major depression is warranted.

Another line of evidence comes from neurodevelopmental literature. Throughout adolescence, there is a significant increase in depression and insomnia symptoms as the brain is continuously maturing (Urrila et al., 2017). Following up on findings of reduced myo-inositol in frontal structures like ACC in depressed adults, researchers used proton $1 \mathrm{H}-\mathrm{MRS}$ to investigate frontal cortical myo-inositol in adolescent boys with symptoms of depression and/or insomnia. This study found lower myo-inositol levels in the ACC in boys with more insomnia symptoms. The association remained significant when adjusting for symptoms of depression as a potential confound. Total creatine (tCr) concentrations in the ACC were also negatively correlated with 
insomnia symptoms (Urrila et al., 2017). Since tCr is crucial for cell energy homeostasis (Rae, 2014), the low $\mathrm{tCr}$ levels associated with insomnia could indicate a decreased energy metabolism in the ACC. Based on low myo-inositol, evidence suggested that the development of depression and insomnia symptoms in the maturing brain of adolescents could involve a disturbed secondary-messenger system (Urrila et al., 2017). Thus, MRS studies highlight the metabolic similarities between MDD and insomnia.

\section{NIRS study}

NIRS, yet another noninvasive functional neuroimaging technique uses non-ionizing light to assess spatiotemporal features of brain activity (Boas et al., 2004; Strangman et al., 2002). NIRS allows monitoring of blood flow in the brain by measuring near-infrared light changes. This technique measures regional cerebral blood volume by assessing oxyhemoglobin (oxy- $\mathrm{Hb}$ ) and deoxyhemoglobin (deoxy-Hb) with a high temporal resolution. Oxy- $\mathrm{Hb}$ and deoxy-Hb reflect regional cerebral blood volume changes in the brain (Ohmae et al., 2006). The relationship between the severity of depressive symptoms and oxy- $\mathrm{Hb}$ variations has been studied in MDD patients (Noda et al., 2012). In this study, 30 MDD patients underwent NIRS during a verbal fluency task. This study demonstrated decreased activation of oxy- $\mathrm{Hb}$ in bilateral frontotemporal areas during a verbal fluency task in MDD patients compared to healthy subjects. Frontotemporal activation was also negatively correlated with MDD severity as assessed with the HDRS (Noda et al., 2012). A subsequent analysis of associations with individual items of the depression rating scale indicated more difficulty initiating sleep in participants who had a lower oxy- $\mathrm{Hb}$ response to verbal fluency in the orbitofrontal, dIPFC, frontopolar, and the right premotor area. This study showed reduced PFC activation during verbal fluency in patients with MDD, especially in individuals with early insomnia symptom (i.e. difficulty in initiating sleep). The 
finding is in line with the fMRI finding of attenuated PFC activation during verbal fluency in patients with insomnia (Altena et al., 2008), suggesting functional alteration in a common region between two conditions.

\section{Neuroimaging findings in various MDD subtypes}

Different subtypes and modifiers of depression are specifically defined by a set of clinical features with response to distinctive treatment strategies. Beside clinical features, theories on biological markers such as monoamine systems and brain connectivity networks may help to improve identification of such subtypes. For instance, evidence shows that slow wave activity in the first cycle of sleep is more commonly decreased in atypical depression than melancholic depression (Peterson and Benca, 2006). As discussed earlier, certain depression associated symptoms, such as insomnia in the form of sleep problems, has been investigated in a comparative way for volumetric measures of hippocampus, amygdala, anterior and posterior subgenual cortices changes in patients with melancholic and psychotic MDD (Vassilopoulou et al., 2013). Henceforth, describing this multifaceted association is in line with the aim of imaging studies to improve identification of biologically distinct endophenotypes and, ultimately develop diagnostic neuro/bio- physiologic markers for psychiatric disorders (Kim and Hwa-Young, 2015; Strakowski, 2018). Another line of evidence emerges from studies searching for neuroimaging markers to differentiate bipolar depressive disorder (BDD) from MDD in their early stage given the diagnostic complications. One study demonstrated that although both BDD and MDD patients had failure to deactivate mPFC compared to healthy controls, BDD subjects showed higher failure of deactivation in the mPFC compared to MDD patients (Rodriguez-Cano et al., 2017). Albeit, the potential effect of medication on certain syndrome clusters and their sleep symptom architecture still remain to be examined. Importantly, due to the differences in methods 
used and results obtained, there is as of yet no compelling evidence for differentiating subtypes of depression based on insomnia symptoms. Since subtypes of depression respond differently to treatment strategies of sleep problems, this avenue of research could prove promising in the future for further treatment development and management planning.

\section{The monoamine system impairment in depression and insomnia}

Considering dysfunction of the monoamine systems in MDD, the serotoninergic system also takes part in regulating sleep and wakefulness cycle (Hirvonen et al., 2008). For example, one PET imaging study of MDD patients investigated the serotonin $1 \mathrm{~A}$ receptor $(5-\mathrm{HT} 1 \mathrm{~A})$ binding potential (Hirvonen et al., 2008). Interestingly, although the binding potential was not associated with overall depression severity, patients with lower binding potential were more likely to experience insomnia. This inverse association was stronger for difficulties initiating sleep than for complaints of early morning awakening (Hirvonen et al., 2008; Woelfer et al., 2018). Selective serotonin reuptake inhibitors (SSRIs) antidepressants, that are commonly prescribed for depression, also increase the levels of GABA in the brain (Bhagwagar et al., 2004; Sanacora et al., 2002). Because sleep medication acts on GABA receptors, it is generally believed that insufficient GABAergic neurotransmission is involved in the etiology of insomnia (Bonnet and Arand, 2010; Morin et al., 2015; Nofzinger et al., 2004; Riemann et al., 2010). Plante and colleagues evaluated this hypothesis using $1 \mathrm{H}-\mathrm{MRS}$ and found that insomnia patients had significantly reduced levels of GABA relative to total creatine (GABA/Cr) in the $A C C$ and occipital cortex, but normal levels in the thalamus (Plante et al., 2012). It has been argued that, although depression can be managed with SSRIs, GABA levels are reduced in depressed patients who have been prescribed anti-anxiety hypnotic medications such as benzodiazepines (Licata et al., 2009). Because benzodiazepines are often added to antidepressants to improve 
sleep quality in MDD (Fava et al., 2011; Fava et al., 2006), it is interesting to evaluate their interaction. In fact, two $1 \mathrm{H}-\mathrm{MRS}$ studies have shown that benzodiazepines reduce GABA in select brain regions and change the effect of SSRIs on GABA reuptake, in panic disorder (Goddard et al., 2004) and in normal population (Licata et al., 2009). One neuroimaging study of 14 MDD patients taking SSRIs revealed that zolpidem increased GABA levels in the ACC and thalamus (Licata et al., 2009).

Another candidate marker in the pathology of depression and insomnia is the alteration of brain metabotropic glutamate receptor 5 (mGluR5). Of note, beside the GABA, glutamate and glutamine are two other metabolites which are directly associated with glutamatergic neurotransmission (Hasler et al., 2007). The mGluR5 is a G protein-coupled receptor which plays an important role in the modulation of neuronal excitability. The changes of mGluR5 expression in the brain regions and their functional impact have been reported from studies of negative mood disorders comparable to MDD (Marsden, 2013). Consistent with this view, sleep deprivation increases availability of mGluRs in the human (Hefti et al., 2013). As such, mGluR5 could provide a promising new target for quality of sleep-wake cycle enhancing compounds development, which may be beneficial in treating disorders such as insomnia (Holst et al., 2017).

In summary, the mentioned findings indicated that disease models of overall abnormal fluctuation of neurotransmitter levels are too simplistic and are not doing justice to the complex interactions that are characteristic of all biological systems. In essence, most of the findings discussed so far, implicated the role of major intrinsic neural networks, which we will discuss in light of insomnia and depression in the following section.

\section{Dysfunction of intrinsic brain networks in depression and Insomnia}


A recent study using 1017 participants from the Human Connectome Project demonstrated that both subjective insomnia symptoms and depressive problems scores are linked with higher functional connectivity between several brain regions including lateral orbitofrontal cortex, dorsolateral prefrontal cortex, anterior and posterior cingulate cortices, insula, parahippocampal gyrus, hippocampus, amygdala, temporal cortex, and precuneus (Cheng et al., 2018). This suggests that intrinsic functional connectivity alter the link between depressive problems and sleep quality. Of note, it has been shown that resting-state brain networks assessed by both fMRI and PET show similar spatial pattern and have the common neural substrate (Savio et al., 2017). In this section, we will discuss the potential role of intrinsic brain network alterations on the common neural basis between depression and insomnia.

9.1. The role of salience network: Neuroimaging studies have demonstrated structural and functional alterations in the PFC, ACC, insula, limbic (including amygdala) and para-limbic regions in both MDD and insomnia (Hajek et al., 2008; Leerssen et al., 2018; Morin et al., 2015; Perico et al., 2005; Vassilopoulou et al., 2013). Some of these regions, including the amygdala, ACC and insula, are key regions of the Salience Network (SN) (Menon, 2011). Worthy of note, insula is involved in detecting and evaluating the stimuli in the regulation process of sympathetic nervous system (Uddin, 2015). Moreover, it has been suggested that aberrant connectivity in the right anterior insula within the $\mathrm{SN}$ is correlated with the severity of depressive symptoms (Manoliu et al., 2014). Also, the right IFG/Al was found to be the key node in the salience network, suggesting that anomalies in this area significantly impact sleep disturbances associated with MDD (Liu et al., 2018). The SN is one of the major intrinsically connected resting state networks and its dysfunction plays a key role in several neuropsychiatric disorders (Menon, 2011; Seeley et al., 2007; Shao et al., 2018). This network is crucial for the detection, 
filtering and integration of emotional, autonomic and introspective information (Uddin, 2015). The available literature in MDD suggests that the SN is hyper-responsive to negative stimuli (Hamilton et al., 2012). Consequently, MDD has been considered as a disorder with large-scale network dysfunction (Kaiser et al., 2015; Menon, 2011). This conceptualization is in line with a neural model of emotion dysregulation in MDD (Rive et al., 2013). Dysfunction of affective control in insomnia has been also suggested to be the result of SN hypersensitivity (Chen et al., 2014). Among the key subcortical regions of the SN, the amygdala is crucial for sensory tuning to enable adaptive responding (Davis and Whalen, 2001; Menon, 2011). Noteworthy that dysfunction of the amygdala in response to emotional processing is a shared phenomenon in the physiopathology of MDD and insomnia (Baglioni et al., 2014; Tahmasian et al., 2013). Hyperactivity of the amygdala has also been reported in insomnia (Nofzinger et al., 2004). For instance, several studies have discussed the bidirectional link between sleep disturbance and emotion dysregulation (Baglioni et al., 2010; Wassing et al., 2016). Findings have indicated that people with insomnia experience more emotion dysregulation during daytime (Jansson-Frojmark et al., 2016) and have insufficient overnight amelioration of emotional distress (Wassing et al., 2016).

Few imaging studies addressed individual differences in insomnia severity within MDD patients. For example, a sMRI study reported a larger amygdala volume in MDD patients with insomnia symptoms compared to MDD patients without insomnia; regardless of the depression subtype e.g. melancholic or psychotic depression (Vassilopoulou et al., 2013). Of note, beside negative emotion processing, the amygdala also takes part in processing of positive emotions and reward processing (Baxter and Murray, 2002). In addition to the amygdala, the striatum and dmPFC also play an important role in reward processing (Casement et al., 2016). These results highlighted higher activity during the reward anticipation in the dmPFC and the association 
between non-restorative sleep in early adolescence, and depressive symptoms in later adolescence. However, surprisingly, no difference was found in amygdala response during anticipation of rewards (Casement et al., 2016). Since previous research has shown a disrupted functional connectivity in emotional brain circuits in insomnia (Huang et al., 2012), it can be argued that arousal in negative emotion is related to poor sleep quality in patients with insomnia symptoms. Consequently, this could be explained by the increased amygdala activity in insomnia disorder (Nofzinger et al., 2004). Hence, it has been reported that patients with insomnia have higher amygdala activity in response to sleep-related stimuli than healthy controls (Baglioni et al., 2014). As mentioned earlier, daytime performance deficits in patients with insomnia could be possibly related to impaired attention and arousal regulation (FortierBrochu et al., 2012). Similarly, it has been revealed that an inability to down-regulate negative emotions is related to mood and anxiety symptoms (Schafer et al., 2017).

Previous genomic findings have demonstrated an association between circadian biological clock and sleep disturbances in patients with insomnia disorder (Morin et al., 2015). The ACC, as the key element of SN, is one of the brain origins of the clock genes and its neural activity disruption is strongly linked to the symptoms of depression (Benedetti et al., 2008). Specifically, there is evidence indicating that the ACC and the vmPFC are the crucial areas in pathophysiology of MDD (Khazaie et al., 2017; Schmaal et al., 2016; Skaf et al., 2002). In addition to being involved in control and integration of emotional behavior, it appears that the ACC and it's dorsal extent plays a key role in decision-making (Benedetti et al., 2008; Critchley et al., 2003). Consistent with these findings, in another study, a moral valence decision task was applied in individuals with MDD. In this classic Go/No-Go attention task participant were asked to react to positive stimuli by pressing a button and ignore the negative distractors, or the opposite. This study demonstrated that the clock genotype in individuals, so-called the Clock genes which regulate circadian rhythm, can affect human behavior, such as the occurrence of 
insomnia during depressive episodes (Benedetti et al., 2008). Moreover, the ventral and rostral parts of the ACC together with hypothalamus, medulla and pons are the main regions involved in autonomic regulation (Critchley et al., 2003). This circuit organizes pattern of sleep and circadian cycle (Devinsky et al., 1995; Saper et al., 2005). Also, the inverse association between the subgenual and rostral ACC with the insomnia parameters in MDD was observed and insomnia severity was negatively correlated with rCBF in the ACC, claustrum and insula (Perico et al., 2005).

9.2. The role of central executive and default mode networks: Highlighting the impaired emotional processes and following the network-based approach, MDD is also characterized by aberrant connectivity within the central executive network (CEN) and default mode network (DMN) (Manoliu et al., 2014). The CEN includes dIPFC and posterior parietal cortex (PPC) and is involved in neurocognitive functions including attention, working memory and top-down emotional regulation (Menon, 2011). The DMN includes the posterior cingulate cortex (PCC), bilateral angular gyri, and mPFC and is involved in self-referential and internally-oriented thoughts during rest (Menon, 2011). Abnormalities in intrinsic functional connectivity within the DMN in MDD have been reported (Manoliu et al., 2014; Menon, 2011). In particular, individuals with MDD present with a lower functional connectivity between the DMN and CEN and a higher functional connectivity between the SN and DMN (Manoliu et al., 2014). Providing an explicit account, the subgenual cingulate and the ventromedial PFC (vmPFC) show enhanced connectivity with other nodes of the DMN in MDD (Hamilton et al., 2015). Moreover, the DMN plays an important role in conscious awareness (Horovitz et al., 2009). It has been argued that sleep deprivation, like what could happen in insomnia, leads to DMN disruption (De Havas et al., 2012). Also, compared to health controls, insomnia patients have shown increased activation of the central DMN areas during self-reference tasks (Marques et al., 2018). Thus, one can 
postulate that disruptions in DMN brain regions may be linked to insomnia disorder. Taken together, the above-mentioned patterns might highlight the potential involvement of the three main intrinsic networks (SN, CEN and DMN) in both MDD and insomnia (Figure 2). Generally, abnormalities in the mentioned intrinsic brain networks are observed in both depression and insomnia, which could address a wide range of issues pertaining to the treatment and underlying pathophysiology of these two conditions. In short and in addition to more localized patterns, understanding of both MDD and Insomnia as network disorders could be referred to the substantial altered disturbance between above mentioned networks.

\section{Limitations}

Scant number of studies was included in this review. The review was limited to EnglishLanguage articles. The applied methods for assessing structural and functional neural mechanisms of insomnia and depression were inconsistent, which in turn hinders meta-analytic procedures. Additionally, based on our selection criteria, quality control of the included studies has not been done. More rigorous quality control of the studies could be obtained through bias assessments in future studies with more included manuscripts and in the context of metaanalysis. Of note, the neuroimaging results are mainly association, not causations. Future studies would help to determine the relationship between insomnia and MDD as cause and effect, and the role of possible moderating/mediating factors.

\section{Conclusion}

The present review provided an overview of neuroimaging studies addressing neural correlates of insomnia in MDD. In summary, neuroimaging helps understanding of the underlying neural mechanisms and the association between MDD and insomnia. The approach of exploring the 
association between these two conditions in form of neural networks, genetic, and the brain monoamine theories might affect research and treatment planning and outcomes. Based on the available limited evidence, abnormalities in the intrinsic brain networks are observed in depression and insomnia studies separately, which could address a wide range of issues pertaining to the treatment and underlying pathophysiology of these two conditions. In other words, understanding of both MDD and insomnia as brain network disorders could refer to the substantial altered disturbance between above mentioned networks in addition to more localized patterns. Especially, structural and functional abnormalities in the PCC and mPFC within the DMN and also the amygdala, insula and ACC within the SN have been observed in each condition separately. Thus, specifying similarities and differences in patients with both symptoms, aside from potentially disruption of connectivity patterns, might guide future studies and facilitate their better understanding in terms of pathophysiology, and potentially develop specific treatments that could target these networks. Moreover, future neuroimaging studies

should use larger sample size, well-characterized patients in terms of diagnosis criteria, severity of symptoms, and control for other comorbidities. In addition, following the standard preprocessing and analysis protocols might help elucidation of the common pathophysiological mechanisms between depression and insomnia.

\section{Acknowledgments}

This work was mainly supported by the Kermanshah University of Medical Sciences and Shahid Beheshti University.

\section{Funding}

The authors received no support by any funding agency for this work. 


\section{Conflict of interest statement}

The authors declare that the research was conducted in the absence of any commercial or financial relationships that could be construed as a potential conflict of interest. 


\section{References}

Abe, H., Honma, S., Namihira, M., Masubuchi, S., Ikeda, M., Ebihara, S., Honma, K., 2001. Clock gene expressions in the suprachiasmatic nucleus and other areas of the brain during rhythm splitting in CS mice. Brain Res Mol Brain Res 87, 92-99.

Adrien, J., 2002. Neurobiological bases for the relation between sleep and depression. Sleep Med Rev 6, 341351.

Altena, E., Van Der Werf, Y.D., Sanz-Arigita, E.J., Voorn, T.A., Rombouts, S.A., Kuijer, J.P., Van Someren, E.J., 2008. Prefrontal hypoactivation and recovery in insomnia. Sleep 31, 1271-1276.

American Psychiatric Association, 2013. Diagnostic and Statistical Manual of Mental Disorders, 5th ed, Washington, DC.

Baglioni, C., Battagliese, G., Feige, B., Spiegelhalder, K., Nissen, C., Voderholzer, U., Lombardo, C., Riemann, D., 2011. Insomnia as a predictor of depression: a meta-analytic evaluation of longitudinal epidemiological studies. J Affect Disord 135, 10-19.

Baglioni, C., Spiegelhalder, K., Lombardo, C., Riemann, D., 2010. Sleep and emotions: a focus on insomnia. Sleep Med Rev 14, 227-238.

Baglioni, C., Spiegelhalder, K., Regen, W., Feige, B., Nissen, C., Lombardo, C., Violani, C., Hennig, J., Riemann, D., 2014. Insomnia disorder is associated with increased amygdala reactivity to insomnia-related stimuli. Sleep 37, 1907-1917.

Baxter, M.G., Murray, E.A., 2002. The amygdala and reward. Nat Rev Neurosci 3, 563-573.

Benedetti, F., Radaelli, D., Bernasconi, A., Dallaspezia, S., Falini, A., Scotti, G., Lorenzi, C., Colombo, C., Smeraldi, E., 2008. Clock genes beyond the clock: CLOCK genotype biases neural correlates of moral valence decision in depressed patients. Genes Brain Behav 7, 20-25.

Bhagwagar, Z., Wylezinska, M., Jezzard, P., Evans, J., Boorman, E., P, M.M., P, J.C., 2008. Low GABA concentrations in occipital cortex and anterior cingulate cortex in medication-free, recovered depressed patients. Int J Neuropsychopharmacol 11, 255-260.

Bhagwagar, Z., Wylezinska, M., Taylor, M., Jezzard, P., Matthews, P.M., Cowen, P.J., 2004. Increased brain GABA concentrations following acute administration of a selective serotonin reuptake inhibitor. Am J Psychiatry $161,368-370$.

Boas, D.A., Dale, A.M., Franceschini, M.A., 2004. Diffuse optical imaging of brain activation: approaches to optimizing image sensitivity, resolution, and accuracy. Neuroimage 23 Suppl 1, S275-288.

Bonnet, M.H., Arand, D.L., 2010. Hyperarousal and insomnia: state of the science. Sleep Med Rev 14, 9-15.

Bora, E., Fornito, A., Pantelis, C., Yücel, M., 2012. Gray matter abnormalities in Major Depressive Disorder: A meta-analysis of voxel based morphometry studies. Journal of Affective Disorders 138, 9-18.

Bunge, S.A., Kahn, I., 2009. Cognition: An Overview of Neuroimaging Techniques A2 - Squire, Larry R, Encyclopedia of Neuroscience. Academic Press, Oxford, pp. 1063-1067.

Casement, M.D., Keenan, K.E., Hipwell, A.E., Guyer, A.E., Forbes, E.E., 2016. Neural Reward Processing Mediates the Relationship between Insomnia Symptoms and Depression in Adolescence. Sleep 39, 439-447. 
Catana, C., Guimaraes, A.R., Rosen, B.R., 2013. PET and MR imaging: the odd couple or a match made in heaven? Journal of nuclear medicine : official publication, Society of Nuclear Medicine 54, 815-824.

Chen, M.C., Chang, C., Glover, G.H., Gotlib, I.H., 2014. Increased insula coactivation with salience networks in insomnia. Biol Psychol 97, 1-8.

Cheng, W., Rolls, E.T., Ruan, H., Feng, J., 2018. Functional Connectivities in the Brain That Mediate the Association Between Depressive Problems and Sleep Quality. JAMA Psychiatry 75, 1052-1061.

Critchley, H.D., Mathias, C.J., Josephs, O., O'Doherty, J., Zanini, S., Dewar, B.K., Cipolotti, L., Shallice, T., Dolan, R.J., 2003. Human cingulate cortex and autonomic control: converging neuroimaging and clinical evidence. Brain 126, 2139-2152.

Davis, M., Whalen, P.J., 2001. The amygdala: vigilance and emotion. Mol Psychiatry 6, 13-34.

De Havas, J.A., Parimal, S., Soon, C.S., Chee, M.W., 2012. Sleep deprivation reduces default mode network connectivity and anti-correlation during rest and task performance. Neuroimage 59, 1745-1751.

Desseilles, M., Dang-Vu, T., Schabus, M., Sterpenich, V., Maquet, P., Schwartz, S., 2008. Neuroimaging insights into the pathophysiology of sleep disorders. Sleep 31, 777-794.

Desseilles, M., Vu, T.D., Maquet, P., 2011. Functional neuroimaging in sleep, sleep deprivation, and sleep disorders. Handb Clin Neurol 98, 71-94.

Devinsky, O., Morrell, M.J., Vogt, B.A., 1995. Contributions of anterior cingulate cortex to behaviour. Brain 118 (Pt 1), 279-306.

Edinger, J.D., Bonnet, M.H., Bootzin, R.R., Doghramji, K., Dorsey, C.M., Espie, C.A., Jamieson, A.O., McCall, W.V., Morin, C.M., Stepanski, E.J., American Academy of Sleep Medicine Work, G., 2004. Derivation of research diagnostic criteria for insomnia: report of an American Academy of Sleep Medicine Work Group. Sleep 27, 1567-1596.

Emamian, F., Khazaie, H., Okun, M.L., Tahmasian, M., Sepehry, A.A., 2019. Link between insomnia and perinatal depressive symptoms: A meta-analysis. J Sleep Res, e12858.

Fava, M., Asnis, G.M., Shrivastava, R.K., Lydiard, B., Bastani, B., Sheehan, D.V., Roth, T., 2011. Improved insomnia symptoms and sleep-related next-day functioning in patients with comorbid major depressive disorder and insomnia following concomitant zolpidem extended-release $12.5 \mathrm{mg}$ and escitalopram treatment: a randomized controlled trial. J Clin Psychiatry 72, 914-928.

Fava, M., McCall, W.V., Krystal, A., Wessel, T., Rubens, R., Caron, J., Amato, D., Roth, T., 2006. Eszopiclone coadministered with fluoxetine in patients with insomnia coexisting with major depressive disorder. Biol Psychiatry 59, 1052-1060.

Fortier-Brochu, É., Beaulieu-Bonneau, S., Ivers, H., Morin, C.M., 2012. Insomnia and daytime cognitive performance: A meta-analysis. Sleep Medicine Reviews 16, 83-94.

Franzen, P.L., Buysse, D.J., 2008. Sleep disturbances and depression: risk relationships for subsequent depression and therapeutic implications. Dialogues Clin Neurosci 10, 473-481.

Fung, S.J., Xi, M., Zhang, J., Torterolo, P., Sampogna, S., Morales, F.R., Chase, M.H., 2011. Projection Neurons from The Central Nucleus of The Amygdala to The Nucleus Pontis Oralis. Journal of Neuroscience Research $89,429-436$. 
Goddard, A.W., Mason, G.F., Appel, M., Rothman, D.L., Gueorguieva, R., Behar, K.L., Krystal, J.H., 2004. Impaired GABA neuronal response to acute benzodiazepine administration in panic disorder. Am J Psychiatry 161, 2186-2193.

Hajek, T., Kozeny, J., Kopecek, M., Alda, M., Hoschl, C., 2008. Reduced subgenual cingulate volumes in mood disorders: a meta-analysis. J Psychiatry Neurosci 33, 91-99.

Hamilton, J.P., Etkin, A., Furman, D.J., Lemus, M.G., Johnson, R.F., Gotlib, I.H., 2012. Functional neuroimaging of major depressive disorder: a meta-analysis and new integration of base line activation and neural response data. Am J Psychiatry 169, 693-703.

Hamilton, J.P., Farmer, M., Fogelman, P., Gotlib, I.H., 2015. Depressive Rumination, the Default-Mode Network, and the Dark Matter of Clinical Neuroscience. Biol Psychiatry 78, 224-230.

Hammerschlag, A.R., Stringer, S., de Leeuw, C.A., Sniekers, S., Taskesen, E., Watanabe, K., Blanken, T.F., Dekker, K., te Lindert, B.H.W., Wassing, R., Jonsdottir, I., Thorleifsson, G., Stefansson, H., Gislason, T., Berger, K., Schormair, B., Wellmann, J., Winkelmann, J., Stefansson, K., Oexle, K., Van Someren, E.J.W., Posthuma, D., 2017. Genome-wide association analysis of insomnia complaints identifies risk genes and genetic overlap with psychiatric and metabolic traits. Nature Genetics 49, 1584.

Hasler, G., van der Veen, J.W., Tumonis, T., Meyers, N., Shen, J., Drevets, W.C., 2007. Reduced prefrontal glutamate/glutamine and gamma-aminobutyric acid levels in major depression determined using proton magnetic resonance spectroscopy. Arch Gen Psychiatry 64, 193-200.

Hefti, K., Holst, S.C., Sovago, J., Bachmann, V., Buck, A., Ametamey, S.M., Scheidegger, M., Berthold, T., GomezMancilla, B., Seifritz, E., Landolt, H.P., 2013. Increased metabotropic glutamate receptor subtype 5 availability in human brain after one night without sleep. Biol Psychiatry 73, 161-168.

Hirsch, G.V., Bauer C.M. and Merabet, L.B., 2015. Using structural and functional brain imaging to uncover how the brain adapts to blindness. Annals of Neuroscience and Psychology, 2:5.

Hirvonen, J., Karlsson, H., Kajander, J., Lepola, A., Markkula, J., Rasi-Hakala, H., Nagren, K., Salminen, J.K., Hietala, J., 2008. Decreased brain serotonin 5-HT1A receptor availability in medication-naive patients with major depressive disorder: an in-vivo imaging study using PET and [carbonyl-11C]WAY-100635. Int J Neuropsychopharmacol 11, 465-476.

Hoh, C.K., 2007. Clinical use of FDG PET. Nuclear Medicine and Biology 34, 737-742.

Holst, S.C., Sousek, A., Hefti, K., Saberi-Moghadam, S., Buck, A., Ametamey, S.M., Scheidegger, M., Franken, P., Henning, A., Seifritz, E., Tafti, M., Landolt, H.P., 2017. Cerebral mGluR5 availability contributes to elevated sleep need and behavioral adjustment after sleep deprivation. Elife 6.

Horovitz, S.G., Braun, A.R., Carr, W.S., Picchioni, D., Balkin, T.J., Fukunaga, M., Duyn, J.H., 2009. Decoupling of the brain's default mode network during deep sleep. Proc Natl Acad Sci U S A 106, 11376-11381.

Huang, Z., Liang, P., Jia, X., Zhan, S., Li, N., Ding, Y., Lu, J., Wang, Y., Li, K., 2012. Abnormal amygdala connectivity in patients with primary insomnia: evidence from resting state fMRI. Eur J Radiol 81, 1288-1295.

Hung, C.M., Li, Y.C., Chen, H.J., Lu, K., Liang, C.L., Liliang, P.C., Tsai, Y.D., Wang, K.W., 2018. Risk of dementia in patients with primary insomnia: a nationwide population-based case-control study. BMC Psychiatry 18, 38.

Jansen, J.F., Backes, W.H., Nicolay, K., Kooi, M.E., 2006. 1H MR spectroscopy of the brain: absolute quantification of metabolites. Radiology 240, 318-332. 
Jansen, P.R., Watanabe, K., Stringer, S., Skene, N., Bryois, J., Hammerschlag, A.R., de Leeuw, C.A., Benjamins, J., Munoz-Manchado, A.B., Nagel, M., Savage, J.E., Tiemeier, H., White, T., Tung, J.Y., Hinds, D.A., Vacic, V., Sullivan, P.F., van der Sluis, S., Polderman, T.J., Smit, A.B., Hjerling-Leffler, J., van Someren, E.J., Posthuma, D., 2018. Genome-wide Analysis of Insomnia (N=1,331,010) Identifies Novel Loci and Functional Pathways. bioRxiv.

Jansson-Frojmark, M., Norell-Clarke, A., Linton, S.J., 2016. The role of emotion dysregulation in insomnia: Longitudinal findings from a large community sample. Br J Health Psychol 21, 93-113.

Javaheipour, N., Shahdipour, N., Noori, K., Zarei, M., Camilleri, J.A., Laird, A.R., Fox, P.T., Eickhoff, S.B., Eickhoff, C.R., Rosenzweig, I., Khazaie, H., Tahmasian, M., 2019. Functional brain alterations in acute sleep deprivation: An activation likelihood estimation meta-analysis. Sleep Med Rev 46, 64-73.

Joo, E.Y., Kim, H., Suh, S., Hong, S.B., 2014. Hippocampal substructural vulnerability to sleep disturbance and cognitive impairment in patients with chronic primary insomnia: magnetic resonance imaging morphometry. Sleep 37, 1189-1198.

Kaiser, R.H., Andrews-Hanna, J.R., Wager, T.D., Pizzagalli, D.A., 2015. Large-Scale Network Dysfunction in Major Depressive Disorder: A Meta-analysis of Resting-State Functional Connectivity. JAMA Psychiatry 72, 603-611.

Kambeitz, J., Cabral, C., Sacchet, M.D., Gotlib, I.H., Zahn, R., Serpa, M.H., Walter, M., Falkai, P., Koutsouleris, N., 2017. Detecting Neuroimaging Biomarkers for Depression: A Meta-analysis of Multivariate Pattern Recognition Studies. Biol Psychiatry 82, 330-338.

Kaufman, J., DeLorenzo, C., Choudhury, S., Parsey, R.V., 2016. The 5-HT<sub $>1$ A </sub $>$ receptor in Major Depressive Disorder. European Neuropsychopharmacology 26, 397-410.

Kessler, R.C., Angermeyer, M., Anthony, J.C., R, D.E.G., Demyttenaere, K., Gasquet, I., G, D.E.G., Gluzman, S., Gureje, O., Haro, J.M., Kawakami, N., Karam, A., Levinson, D., Medina Mora, M.E., Oakley Browne, M.A., PosadaVilla, J., Stein, D.J., Adley Tsang, C.H., Aguilar-Gaxiola, S., Alonso, J., Lee, S., Heeringa, S., Pennell, B.E., Berglund, P., Gruber, M.J., Petukhova, M., Chatterji, S., Ustun, T.B., 2007. Lifetime prevalence and age-of-onset distributions of mental disorders in the World Health Organization's World Mental Health Survey Initiative. World Psychiatry 6, 168-176.

Khazaie, H., Ghadami, M.R., Knight, D.C., Emamian, F., Tahmasian, M., 2013. Insomnia treatment in the third trimester of pregnancy reduces postpartum depression symptoms: a randomized clinical trial. Psychiatry Res $210,901-905$.

Khazaie, H., Veronese, M., Noori, K., Emamian, F., Zarei, M., Ashkan, K., Leschziner, G.D., Eickhoff, C.R., Eickhoff, S.B., Morrell, M.J., Osorio, R.S., Spiegelhalder, K., Tahmasian, M., Rosenzweig, I., 2017. Functional reorganization in obstructive sleep apnoea and insomnia: A systematic review of the resting-state fMRI. Neurosci Biobehav Rev 77, 219-231.

Kim, Y.-K., Hwa-Young, L., 2015. Different Mechanisms Between Melancholic and Atypical Depression.

Koolschijn, P.C., van Haren, N.E., Lensvelt-Mulders, G.J., Hulshoff Pol, H.E., Kahn, R.S., 2009. Brain volume abnormalities in major depressive disorder: a meta-analysis of magnetic resonance imaging studies. Hum Brain Mapp 30, 3719-3735.

Lane, J.M., Jones, S., Dashti, H., Wood, A., Aragam, K., van Hees, V.T., Brumpton, B., Winsvold, B.S., Wang, H., Bowden, J., Song, Y., Patel, K., Anderson, S.G., Beaumont, R., Bechtold, D.A., Cade, B., Kathiresan, S., Little, M.A., Luik, A.I.I., Loudon, A.S., Purcell, S., Richmond, R.C., Scheer, F.A., Tyrrell, J., Winkelman, J., Strand, L.B., Nielsen, J.B., Willer, C.J., Redline, S., Spiegelhalder, K., Kyle, S.D., Ray, D.W., Zwart, J.A., Hveem, K., Frayling, T.M., Lawlor, 
D.A., Rutter, M.K., Weedon, M.N., Saxena, R., 2018. Biological and clinical insights from genetics of insomnia symptoms. bioRxiv.

Leerssen, J., Wassing, R., Ramautar, J.R., Stoffers, D., Lakbila-Kamal, O., Perrier, J., Bruijel, J., Foster-Dingley, J.C., Aghajani, M., van Someren, E.J.W., 2018. Increased hippocampal-prefrontal functional connectivity in insomnia. Neurobiol Learn Mem.

Lepine, J.P., Briley, M., 2011. The increasing burden of depression. Neuropsychiatr Dis Treat 7, 3-7.

Licata, S.C., Jensen, J.E., Penetar, D.M., Prescot, A.P., Lukas, S.E., Renshaw, P.F., 2009. A therapeutic dose of zolpidem reduces thalamic GABA in healthy volunteers: a proton MRS study at 4 T. Psychopharmacology (Berl) 203, 819-829.

Liu, C.-H., Guo, J., Lu, S.-L., Tang, L.-R., Fan, J., Wang, C.-Y., Wang, L., Liu, Q.-Q., Liu, C.-Z., 2018. Increased Salience Network Activity in Patients With Insomnia Complaints in Major Depressive Disorder. Frontiers in Psychiatry 9.

Liu, S., Cai, W., Liu, S., Zhang, F., Fulham, M., Feng, D., Pujol, S., Kikinis, R., 2015. Multimodal neuroimaging computing: a review of the applications in neuropsychiatric disorders. Brain Inform 2, 167-180.

Lowrey, P.L., Takahashi, J.S., 2000. Genetics of the mammalian circadian system: Photic entrainment, circadian pacemaker mechanisms, and posttranslational regulation. Annu Rev Genet 34, 533-562.

Manoliu, A., Meng, C., Brandl, F., Doll, A., Tahmasian, M., Scherr, M., Schwerthöffer, D., Zimmer, C., Förstl, H., Bäuml, J., Riedl, V., Wohlschläger, A., Sorg, C., 2014. Insular dysfunction within the salience network is associated with severity of symptoms and aberrant inter-network connectivity in major depressive disorder. Frontiers in Human Neuroscience 7.

Marques, D.R., Gomes, A.A., Caetano, G., Castelo-Branco, M., 2018. Insomnia Disorder and Brain's DefaultMode Network. Curr Neurol Neurosci Rep 18, 45.

Marsden, W.N., 2013. Synaptic plasticity in depression: molecular, cellular and functional correlates. Prog Neuropsychopharmacol Biol Psychiatry 43, 168-184.

Mayberg, H.S., Brannan, S.K., Mahurin, R.K., Jerabek, P.A., Brickman, J.S., Tekell, J.L., Silva, J.A., McGinnis, S., Glass, T.G., Martin, C.C., Fox, P.T., 1997. Cingulate function in depression: a potential predictor of treatment response. Neuroreport 8, 1057-1061.

Mayberg, H.S., Liotti, M., Brannan, S.K., McGinnis, S., Mahurin, R.K., Jerabek, P.A., Silva, J.A., Tekell, J.L., Martin, C.C., Lancaster, J.L., Fox, P.T., 1999. Reciprocal limbic-cortical function and negative mood: converging PET findings in depression and normal sadness. Am J Psychiatry 156, 675-682.

Menon, V., 2011. Large-scale brain networks and psychopathology: a unifying triple network model. Trends Cogn Sci 15, 483-506.

Moher, D., Liberati, A., Tetzlaff, J., Altman, D.G., Group, P., 2009. Preferred reporting items for systematic reviews and meta-analyses: the PRISMA statement. PLoS Med 6, e1000097.

Morin, C.M., Drake, C.L., Harvey, A.G., Krystal, A.D., Manber, R., Riemann, D., Spiegelhalder, K., 2015. Insomnia disorder. Nat Rev Dis Primers 1, 15026.

Muller, V.I., Cieslik, E.C., Serbanescu, I., Laird, A.R., Fox, P.T., Eickhoff, S.B., 2016. Altered Brain Activity in Unipolar Depression Revisited: Meta-analyses of Neuroimaging Studies. JAMA Psychiatry. 
Muller, V.I., Cieslik, E.C., Serbanescu, I., Laird, A.R., Fox, P.T., Eickhoff, S.B., 2017. Altered Brain Activity in Unipolar Depression Revisited: Meta-analyses of Neuroimaging Studies. JAMA Psychiatry 74, 47-55.

Noda, T., Yoshida, S., Matsuda, T., Okamoto, N., Sakamoto, K., Koseki, S., Numachi, Y., Matsushima, E., Kunugi, H., Higuchi, T., 2012. Frontal and right temporal activations correlate negatively with depression severity during verbal fluency task: a multi-channel near-infrared spectroscopy study. J Psychiatr Res 46, 905-912.

Nofzinger, E.A., Buysse, D.J., Germain, A., Price, J.C., Miewald, J.M., Kupfer, D.J., 2004. Functional neuroimaging evidence for hyperarousal in insomnia. Am J Psychiatry 161, 2126-2128.

Ohayon, M.M., Roth, T., 2003. Place of chronic insomnia in the course of depressive and anxiety disorders. J Psychiatr Res 37, 9-15.

Ohmae, E., Ouchi, Y., Oda, M., Suzuki, T., Nobesawa, S., Kanno, T., Yoshikawa, E., Futatsubashi, M., Ueda, Y., Okada, H., Yamashita, Y., 2006. Cerebral hemodynamics evaluation by near-infrared time-resolved spectroscopy: correlation with simultaneous positron emission tomography measurements. Neuroimage 29 , 697-705.

Okun, M.L., 2016. Disturbed Sleep and Postpartum Depression. Curr Psychiatry Rep 18, 66.

Park, S.C., Kim, J.M., Jun, T.Y., Lee, M.S., Kim, J.B., Jeong, S.H., Park, Y.C., 2013. Prevalence and Clinical Correlates of Insomnia in Depressive Disorders: The CRESCEND Study. Psychiatry Investig 10, 373-381.

Perico, C.A., Skaf, C.R., Yamada, A., Duran, F., Buchpiguel, C.A., Castro, C.C., Soares, J.C., Busatto, G.F., 2005. Relationship between regional cerebral blood flow and separate symptom clusters of major depression: a single photon emission computed tomography study using statistical parametric mapping. Neurosci Lett 384, 265-270.

Perlis, M.L., Smith, L.J., Lyness, J.M., Matteson, S.R., Pigeon, W.R., Jungquist, C.R., Tu, X., 2006. Insomnia as a risk factor for onset of depression in the elderly. Behav Sleep Med 4, 104-113.

Peterson, M.J., Benca, R.M., 2006. Sleep in mood disorders. Psychiatr Clin North Am 29, 1009-1032; abstract ix.

Plante, D.T., Jensen, J.E., Schoerning, L., Winkelman, J.W., 2012. Reduced gamma-aminobutyric acid in occipital and anterior cingulate cortices in primary insomnia: a link to major depressive disorder?

Neuropsychopharmacology 37, 1548-1557.

Price, R.B., Shungu, D.C., Mao, X., Nestadt, P., Kelly, C., Collins, K.A., Murrough, J.W., Charney, D.S., Mathew, S.J., 2009. Amino acid neurotransmitters assessed by proton magnetic resonance spectroscopy: relationship to treatment resistance in major depressive disorder. Biol Psychiatry 65, 792-800.

Rae, C.D., 2014. A guide to the metabolic pathways and function of metabolites observed in human brain $1 \mathrm{H}$ magnetic resonance spectra. Neurochem Res 39, 1-36.

Rahmim, A., Zaidi, H., 2008. PET versus SPECT: strengths, limitations and challenges. Nucl Med Commun 29, 193-207.

Riemann, D., Spiegelhalder, K., Feige, B., Voderholzer, U., Berger, M., Perlis, M., Nissen, C., 2010. The hyperarousal model of insomnia: a review of the concept and its evidence. Sleep Med Rev 14, 19-31.

Riemann, D., Voderholzer, U., Spiegelhalder, K., Hornyak, M., Buysse, D.J., Nissen, C., Hennig, J., Perlis, M.L., van Elst, L.T., Feige, B., 2007. Chronic insomnia and MRI-measured hippocampal volumes: a pilot study. Sleep 30, 955-958. 
Ritchey, M., Dolcos, F., Eddington, K.M., Strauman, T.J., Cabeza, R., 2011. Neural correlates of emotional processing in depression: changes with cognitive behavioral therapy and predictors of treatment response. J Psychiatr Res 45, 577-587.

Rive, M.M., van Rooijen, G., Veltman, D.J., Phillips, M.L., Schene, A.H., Ruhe, H.G., 2013. Neural correlates of dysfunctional emotion regulation in major depressive disorder. A systematic review of neuroimaging studies. Neurosci Biobehav Rev 37, 2529-2553.

Rodriguez-Cano, E., Alonso-Lana, S., Sarro, S., Fernandez-Corcuera, P., Goikolea, J.M., Vieta, E., Maristany, T., Salvador, R., McKenna, P.J., Pomarol-Clotet, E., 2017. Differential failure to deactivate the default mode network in unipolar and bipolar depression. Bipolar Disord 19, 386-395.

Ross, B., Bluml, S., 2001. Magnetic resonance spectroscopy of the human brain. The Anatomical Record 265, 54-84.

Sanacora, G., Mason, G.F., Rothman, D.L., Krystal, J.H., 2002. Increased occipital cortex GABA concentrations in depressed patients after therapy with selective serotonin reuptake inhibitors. The American journal of psychiatry 159, 663-665.

Saper, C.B., Scammell, T.E., Lu, J., 2005. Hypothalamic regulation of sleep and circadian rhythms. Nature 437, 1257-1263.

Sataloff, R.T., Mandel, S., Muscal, E., Park, C.H., Rosen, D.C., Kim, S.M., Spiegel, J.R., 1996. Single-photonemission computed tomography (SPECT) in neurotologic assessment: a preliminary report. Am J Otol 17, 909-916.

Savio, A., Funger, S., Tahmasian, M., Rachakonda, S., Manoliu, A., Sorg, C., Grimmer, T., Calhoun, V., Drzezga, A., Riedl, V., Yakushev, I., 2017. Resting-State Networks as Simultaneously Measured with Functional MRI and PET. J Nucl Med 58, 1314-1317.

Schafer, J.O., Naumann, E., Holmes, E.A., Tuschen-Caffier, B., Samson, A.C., 2017. Emotion Regulation Strategies in Depressive and Anxiety Symptoms in Youth: A Meta-Analytic Review. J Youth Adolesc 46, 261-276.

Schmaal, L., Veltman, D.J., van Erp, T.G., Samann, P.G., Frodl, T., Jahanshad, N., Loehrer, E., Tiemeier, H., Hofman, A., Niessen, W.J., Vernooij, M.W., Ikram, M.A., Wittfeld, K., Grabe, H.J., Block, A., Hegenscheid, K., Volzke, H., Hoehn, D., Czisch, M., Lagopoulos, J., Hatton, S.N., Hickie, I.B., Goya-Maldonado, R., Kramer, B., Gruber, O., Couvy-Duchesne, B., Renteria, M.E., Strike, L.T., Mills, N.T., de Zubicaray, G.I., McMahon, K.L., Medland, S.E., Martin, N.G., Gillespie, N.A., Wright, M.J., Hall, G.B., MacQueen, G.M., Frey, E.M., Carballedo, A., van Velzen, L.S., van Tol, M.J., van der Wee, N.J., Veer, I.M., Walter, H., Schnell, K., Schramm, E., Normann, C., Schoepf, D., Konrad, C., Zurowski, B., Nickson, T., McIntosh, A.M., Papmeyer, M., Whalley, H.C., Sussmann, J.E., Godlewska, B.R., Cowen, P.J., Fischer, F.H., Rose, M., Penninx, B.W., Thompson, P.M., Hibar, D.P., 2016.

Subcortical brain alterations in major depressive disorder: findings from the ENIGMA Major Depressive Disorder working group. Mol Psychiatry 21, 806-812.

Seeley, W.W., Menon, V., Schatzberg, A.F., Keller, J., Glover, G.H., Kenna, H., Reiss, A.L., Greicius, M.D., 2007. Dissociable intrinsic connectivity networks for salience processing and executive control. J Neurosci 27, 2349-2356.

Serretti, A., Benedetti, F., Mandelli, L., Lorenzi, C., Pirovano, A., Colombo, C., Smeraldi, E., 2003. Genetic dissection of psychopathological symptoms: insomnia in mood disorders and CLOCK gene polymorphism. Am J Med Genet B Neuropsychiatr Genet 121B, 35-38. 
Shao, J., Meng, C., Tahmasian, M., Brandl, F., Yang, Q., Luo, G., Luo, C., Yao, D., Gao, L., Riedl, V., Wohlschlager, A., Sorg, C., 2018. Common and distinct changes of default mode and salience network in schizophrenia and major depression. Brain Imaging Behav.

Skaf, C.R., Yamada, A., Garrido, G.E., Buchpiguel, C.A., Akamine, S., Castro, C.C., Busatto, G.F., 2002. Psychotic symptoms in major depressive disorder are associated with reduced regional cerebral blood flow in the subgenual anterior cingulate cortex: a voxel-based single photon emission computed tomography (SPECT) study. J Affect Disord 68, 295-305.

Soehner, A.M., Kaplan, K.A., Harvey, A.G., 2014. Prevalence and clinical correlates of co-occurring insomnia and hypersomnia symptoms in depression. J Affect Disord 167, 93-97.

Spiegelhalder, K., Regen, W., Baglioni, C., Nissen, C., Riemann, D., Kyle, S.D., 2015. Neuroimaging insights into insomnia. Curr Neurol Neurosci Rep 15, 9.

Stein, M.B., McCarthy, M.J., Chen, C.Y., Jain, S., Gelernter, J., He, F., Heeringa, S.G., Kessler, R.C., Nock, M.K., Ripke, S., Sun, X., Wynn, G.H., Smoller, J.W., Ursano, R.J., 2018. Genome-wide analysis of insomnia disorder. Mol Psychiatry.

Strakowski, S.M., 2018. Using Neuroimaging to Develop Mood Disorder Diagnostic Biomarkers: A Good Forward Step and Some Considerations. Biological Psychiatry: Cognitive Neuroscience and Neuroimaging 3, 411-413.

Strangman, G., Boas, D.A., Sutton, J.P., 2002. Non-invasive neuroimaging using near-infrared light. Biol Psychiatry 52, 679-693.

Tahmasian, M., Jamalabadi, H., Abedini, M., Ghadami, M.R., Sepehry, A.A., Knight, D.C., Khazaie, H., 2017. Differentiation chronic post traumatic stress disorder patients from healthy subjects using objective and subjective sleep-related parameters. Neurosci Lett 650, 174-179.

Tahmasian, M., Knight, D.C., Manoliu, A., Schwerthoffer, D., Scherr, M., Meng, C., Shao, J., Peters, H., Doll, A., Khazaie, H., Drzezga, A., Bauml, J., Zimmer, C., Forstl, H., Wohlschlager, A.M., Riedl, V., Sorg, C., 2013. Aberrant intrinsic connectivity of hippocampus and amygdala overlap in the fronto-insular and dorsomedial-prefrontal cortex in major depressive disorder. Front Hum Neurosci 7, 639.

Tahmasian, M., Noori, K., Samea, F., Zarei, M., Spiegelhalder, K., Eickhoff, S.B., Van Someren, E., Khazaie, H., Eickhoff, C.R., 2018. A lack of consistent brain alterations in insomnia disorder: An activation likelihood estimation meta-analysis. Sleep Med Rev 42, 111-118.

Thase, M.E., 2006. Depression and sleep: pathophysiology and treatment. Dialogues Clin Neurosci 8, 217-226.

Tsuno, N., Besset, A., Ritchie, K., 2005. Sleep and depression. J Clin Psychiatry 66, 1254-1269.

Uddin, L.Q., 2015. Salience processing and insular cortical function and dysfunction. Nat Rev Neurosci 16, 5561.

Urrila, A.S., Hakkarainen, A., Castaneda, A., Paunio, T., Marttunen, M., Lundbom, N., 2017. Frontal Cortex MyoInositol Is Associated with Sleep and Depression in Adolescents: A Proton Magnetic Resonance Spectroscopy Study. Neuropsychobiology 75, 21-31.

Vassilopoulou, K., Papathanasiou, M., Michopoulos, I., Boufidou, F., Oulis, P., Kelekis, N., Rizos, E., Nikolaou, C., Pantelis, C., Velakoulis, D., Lykouras, L., 2013. A magnetic resonance imaging study of hippocampal, amygdala and subgenual prefrontal cortex volumes in major depression subtypes: melancholic versus psychotic depression. J Affect Disord 146, 197-204. 
Waraich, P., Goldner, E.M., Somers, J.M., Hsu, L., 2004. Prevalence and incidence studies of mood disorders: a systematic review of the literature. Can J Psychiatry 49, 124-138.

Wassing, R., Benjamins, J.S., Dekker, K., Moens, S., Spiegelhalder, K., Feige, B., Riemann, D., van der Sluis, S., Van Der Werf, Y.D., Talamini, L.M., Walker, M.P., Schalkwijk, F., Van Someren, E.J., 2016. Slow dissolving of emotional distress contributes to hyperarousal. Proc Natl Acad Sci U S A 113, 2538-2543.

Wigmore, E.M., Clarke, T.K., Howard, D.M., Adams, M.J., Hall, L.S., Zeng, Y., Gibson, J., Davies, G., FernandezPujals, A.M., Thomson, P.A., Hayward, C., Smith, B.H., Hocking, L.J., Padmanabhan, S., Deary, I.J., Porteous, D.J., Nicodemus, K.K., McIntosh, A.M., 2017. Do regional brain volumes and major depressive disorder share genetic architecture? A study of Generation Scotland ( $n=19762)$, UK Biobank ( $n=24048)$ and the English Longitudinal Study of Ageing $(n=5766)$. Translational Psychiatry 7, e1205.

Winkelman, J.W., Buxton, O.M., Jensen, J.E., Benson, K.L., O'Connor, S.P., Wang, W., Renshaw, P.F., 2008. Reduced brain GABA in primary insomnia: preliminary data from 4T proton magnetic resonance spectroscopy (1H-MRS). Sleep 31, 1499-1506.

Winkelman, J.W., Plante, D.T., Schoerning, L., Benson, K., Buxton, O.M., O'Connor, S.P., Jensen, J.E., Renshaw, P.F., Gonenc, A., 2013. Increased Rostral Anterior Cingulate Cortex Volume in Chronic Primary Insomnia. Sleep 36, 991-998.

Woelfer, M., Kasties, V., Kahlfuss, S., Walter, M., 2018. The Role of Depressive Subtypes within the Neuroinflammation Hypothesis of Major Depressive Disorder. Neuroscience.

Xi, M., Fung, S.J., Zhang, J., Sampogna, S., Chase, M.H., 2012. The amygdala and the pedunculopontine tegmental nucleus: interactions controlling active (rapid eye movement) sleep. Exp Neurol 238, 44-51. 


\section{Figures' legends}

Figure 1. Paper selection strategy flow chart.

Figure 2. The schematic presentation of symptoms observed in patients with Major depressive disorder (MDD) and insomnia disorder (ID), and their similarity in aberrant functional connectivity in hubs of three major intrinsic networks. Adopted from "Functional Reorganization in Obstructive Sleep Apnoea and Insomnia: A Systematic Review of the Resting-State Functional Neuroimaging" by H. Khazaie et al, 2017, Neurosci Biobehav Rev, 77:219-231 and "Resting-state functional connectivity in major depressive disorder: A review" by P.C. Mulders et al, 2015, Neurosci Biobehav Rev, 56:330-44. 


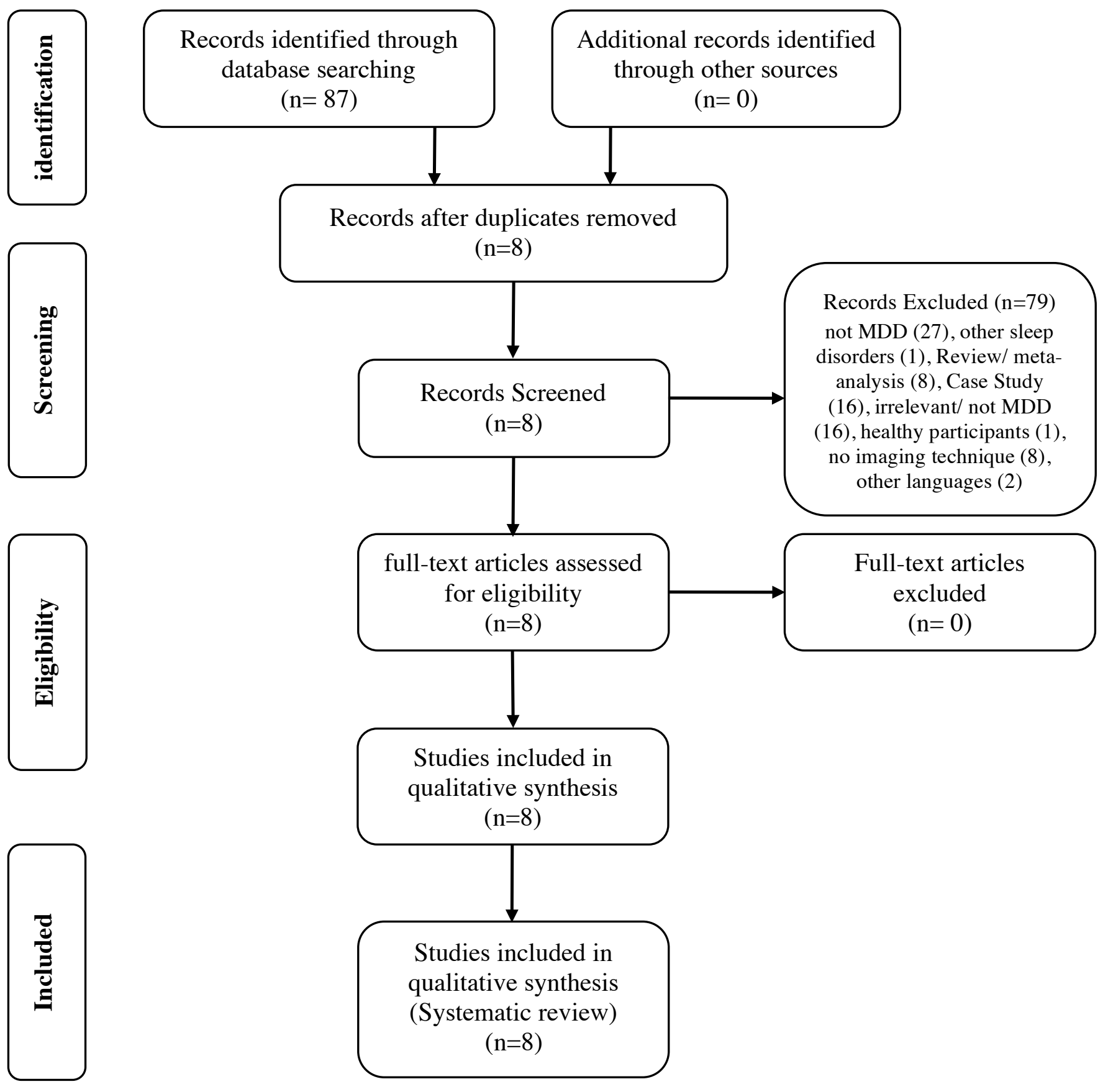

Figure 1. Studies entered into the review are listed based on the year of publication and further alphabetically for each year. MRI= Magnetic Resonance Imaging; fMRI= Functional Magnetic Resonance Imaging; BOLD=Blood Oxygen- level dependent; NIRS= Near- Infrared Spectroscopy; SPECT= Single Photon Emission Computed Tomography; MRS= Magnetic Resonance Spectroscopy; PET= positron emission tomography. 
Major Depressive Disorder

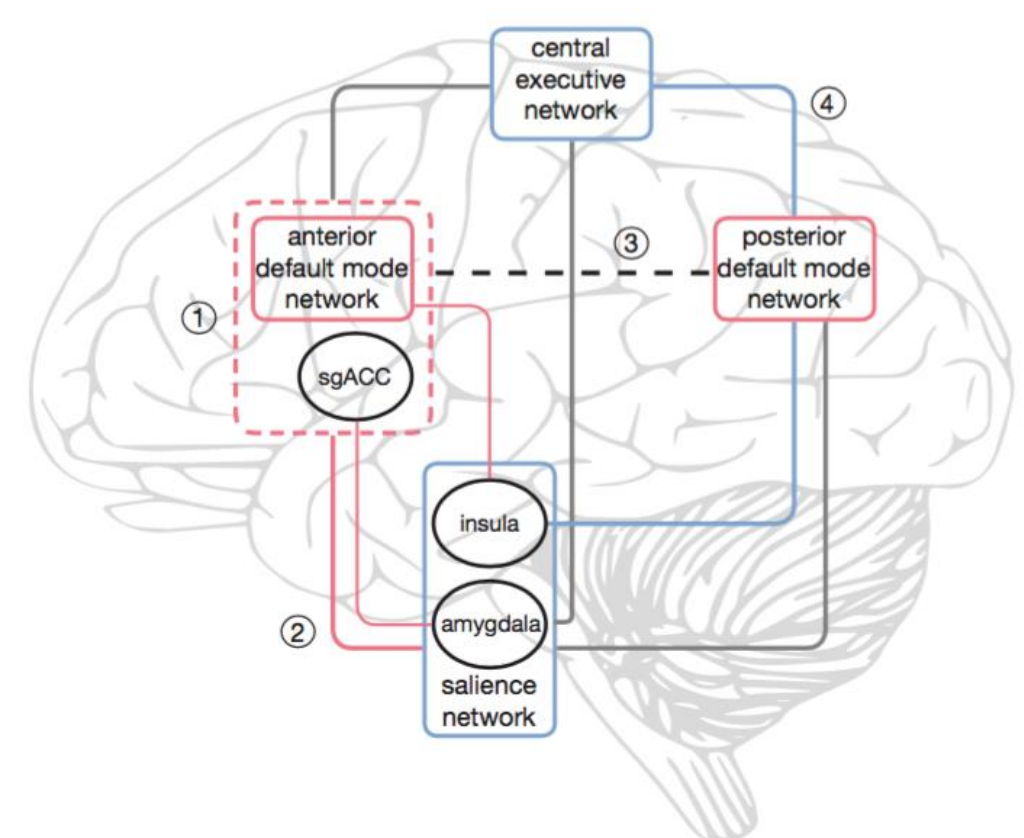

\section{Insomnia Disorder}

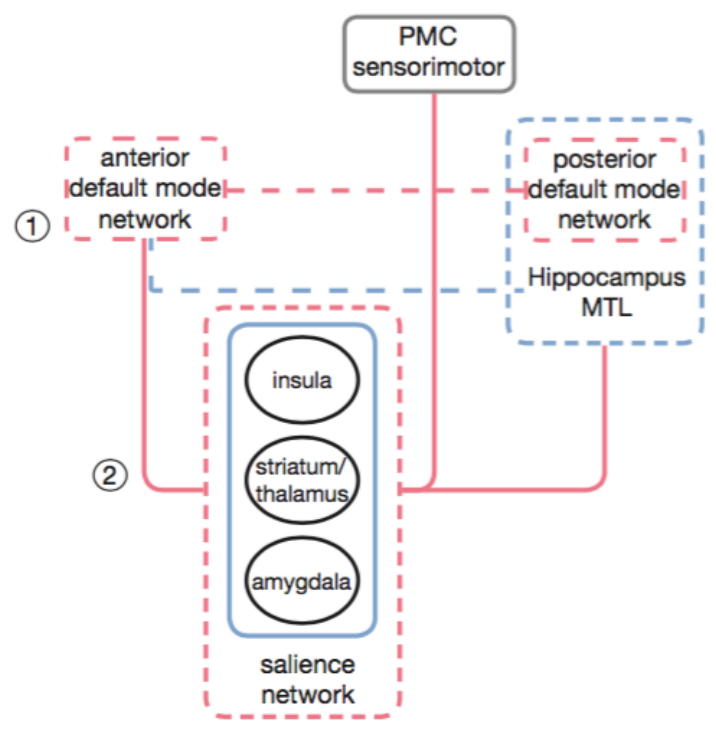

Figure 2. The schematic presentation of symptoms observed in patients with Major depressive disorder (MDD) and insomnia disorder (ID), and their similarity in aberrant functional connectivity in hubs of three major intrinsic networks. Adopted from "Functional Reorganization in Obstructive

Sleep Apnoea and Insomnia: A Systematic Review of the Resting-State Functional Neuroimaging" by H. Khazaie et al, 2017, Neurosci Biobehav Rev, 77:219-231 and

"Resting-state functional connectivity in major depressive disorder: A review" by P.C. Mulders et al, 2015, Neurosci Biobehav Rev, 56:330-44. 
Table 1. Summary of the included studies. m-MMD: Melancholic MDD; p-MDD: Psychotic MDD; Mixed MDD group: Bipolar \& Unipolar Depressed group; HI-MDD: High Insomnia MDD; LI-MDD: Low Insomnia MDD; BDI-IA: Beck Depression Inventory; AIS: Athens Insomnia Scale; fMRI: functional MRI; NIRS: Near-infrared Spectroscopy; HDRS: Hamilton Depression Rating Scale; K-SADS: Schedule for Affective Disorders and Schizophrenia for School-Age Children; DSM: Diagnostic and Structural Manual of Mental Disorders; GAF: Global Assessment of Functioning scale; MMSE: Mini-mental State Examination Scale; MRS: magnetic resonance spectroscopy; PET: positron emission tomography; PSQI: Pittsburg Sleep Quality Index; sMRI: structural magnetic resonance imaging; SPECT: single-photon emission computed tomography; SSS: Stanford Sleepiness Sale; N/S: not specified.

\begin{tabular}{|c|c|c|c|c|c|c|c|c|c|}
\hline Author, year & $\begin{array}{l}\text { Number } \\
\text { of } \\
\text { subjects } \\
\text { (patients/ } \\
\text { controls) }\end{array}$ & $\begin{array}{c}\text { Age } \\
(\text { Mean } \pm \text { SD) }\end{array}$ & Gender & Study Design & $\begin{array}{l}\text { Imaging } \\
\text { Modality }\end{array}$ & $\begin{array}{l}\text { Depression } \\
\text { Subtype }\end{array}$ & $\begin{array}{l}\text { Depression } \\
\text { Scale }\end{array}$ & Insomnia Scale & $\begin{array}{c}\text { Structured } \\
\text { Clinical Interview }\end{array}$ \\
\hline Liu et al, 2018 & $61 / 51$ & $\begin{array}{l}\text { HI-MDD group } \\
\text { (41.33 } \pm 12.51) \\
\text { LI-MDD group } \\
(34.27 \pm 11.23)\end{array}$ & $\begin{array}{l}\text { HI-MDD } \\
\text { group } \\
(12 \mathrm{~F}, 12 \mathrm{M}) ; \\
\text { LI-MDD group } \\
(28 \mathrm{~F}, 9 \mathrm{M})\end{array}$ & $\begin{array}{l}\text { Cross- } \\
\text { Sectional } \\
\text { Study }\end{array}$ & fMRI & $\mathrm{N} / \mathrm{S}$ & HDRS & $\begin{array}{c}\text { HDRS } \\
\text { (Insomnia } \\
\text { symptoms) }\end{array}$ & DSM-IV \\
\hline Urrila et al, 2017 & $9 / 10$ & $\begin{array}{c}\text { MDD group } \\
\text { Age }(16 \pm 0.8)\end{array}$ & All Males & $\begin{array}{l}\text { Cross- } \\
\text { Sectional } \\
\text { Study }\end{array}$ & MRS & $\mathrm{N} / \mathrm{S}$ & $\begin{array}{l}\text { BDI-21 / } \\
\text { HDRS / } \\
\text { K-SADS }\end{array}$ & $\begin{array}{c}\text { AIS } \\
\text { (Insomnia } \\
\text { symptoms) }\end{array}$ & $\begin{array}{l}\text { DSM-IV; Axis I } \\
\text { Disorder / } \\
\text { GAF }\end{array}$ \\
\hline $\begin{array}{l}\text { Casement et al, } \\
2016\end{array}$ & $123 / 0$ & $\begin{array}{c}\text { MDD group } \\
\text { Age } 16(0.87 \pm \\
1.16) ; \\
\text { Age } 17(0.79 \pm \\
1.07)\end{array}$ & All Females & $\begin{array}{l}\text { longitudinal } \\
\text { Study }\end{array}$ & fMRI & $\mathrm{N} / \mathrm{S}$ & K-SADS & $\begin{array}{l}\text { K-SADS } \\
\text { (Insomnia } \\
\text { symptoms) }\end{array}$ & $\begin{array}{l}\text { Semi-structured } \\
\text { interview by a } \\
\text { licensed clinical } \\
\text { psychologist }\end{array}$ \\
\hline $\begin{array}{l}\text { Vassilopolou et al, } \\
2013\end{array}$ & $39 / 18$ & $\begin{array}{l}\text { m-MDD group } \\
(52.09 \pm 8.2) \\
\text { m-MDD group } \\
(52.88 \pm 10.8)\end{array}$ & $\begin{array}{c}\text { m-MDD } \\
(17 \mathrm{~F}, 5 \mathrm{M}) \\
\mathrm{p}-\mathrm{MDD} \\
(12 \mathrm{~F}, 5 \mathrm{M})\end{array}$ & $\begin{array}{l}\text { Cross- } \\
\text { Sectional } \\
\text { Study }\end{array}$ & sMRI & $\begin{array}{l}22 \text { m-MDD } \\
17 \text { m-MDD } \\
18 \text { Control }\end{array}$ & HDRS & $\begin{array}{c}\text { HDRS } \\
\text { (Insomnia } \\
\text { symptoms) }\end{array}$ & $\begin{array}{l}\text { DSM-IIIR / } \\
\text { MMSE }\end{array}$ \\
\hline Noda et al, 2012 & $30 / 30$ & $\begin{array}{l}\text { MDD Group } \\
(36.7 \pm 11.6)\end{array}$ & $(16 \mathrm{~F}, 14 \mathrm{M})$ & $\begin{array}{l}\text { Cross- } \\
\text { Sectional } \\
\text { Study }\end{array}$ & NIRS & $\mathrm{N} / \mathrm{S}$ & HDRS & $\begin{array}{l}\text { HDRS/SSS } \\
\text { (Insomnia } \\
\text { symptoms) }\end{array}$ & $\begin{array}{l}\text { DSM-IV; Axis I } \\
\text { Disorders }\end{array}$ \\
\hline Benedetti et al, 2008 & $30 / 0$ & $\begin{array}{l}\text { Mixed MDD group } \\
50.40 \pm 14.50\end{array}$ & $(20 \mathrm{~F}, 10 \mathrm{M})$ & $\begin{array}{l}\text { Descriptive } \\
\text { Study }\end{array}$ & fMRI & $\begin{array}{l}21 \text { Bipolar } \\
9 \text { Unipolar }\end{array}$ & HDRS & $\begin{array}{c}\text { HDRS } \\
\text { (Insomnia } \\
\text { symptoms) }\end{array}$ & NA \\
\hline Liminnnn at al snne & $01 / 15$ & MDD group & All Enmalno & $\begin{array}{l}\text { Cross- } \\
\text { Sectional }\end{array}$ & DET & NI/C & HDRS / & $\begin{array}{l}\text { HDRS } \\
\text { IInnmmnin }\end{array}$ & DSM-IV; Axis I \\
\hline
\end{tabular}




\begin{tabular}{|c|c|c|c|c|c|c|c|c|c|}
\hline Périco et al, 2005 & $15 / 15$ & $\begin{array}{l}\text { MDD group } \\
(34.5 \pm 10.2)\end{array}$ & $(12 F, 3 \mathrm{M})$ & $\begin{array}{l}\text { Cross- } \\
\text { Sectional } \\
\text { Study }\end{array}$ & SPECT & $\mathrm{N} / \mathrm{S}$ & HDRS & $\begin{array}{c}\text { HDRS } \\
\text { (Insomnia } \\
\text { symptoms) }\end{array}$ & $\begin{array}{l}\text { DSMIV- Patient } \\
\text { Edition (SCID-I/P) }\end{array}$ \\
\hline
\end{tabular}

